This item was submitted to Loughborough's Research Repository by the author.

Items in Figshare are protected by copyright, with all rights reserved, unless otherwise indicated.

\title{
Textile composites from hydro-entangled non-woven fabrics
}

PLEASE CITE THE PUBLISHED VERSION

https://doi.org/10.1016/S0045-7949(99)00167-4

PUBLISHER

(c) Elsevier

VERSION

AM (Accepted Manuscript)

PUBLISHER STATEMENT

This work is made available according to the conditions of the Creative Commons Attribution-NonCommercialNoDerivatives 4.0 International (CC BY-NC-ND 4.0) licence. Full details of this licence are available at: https://creativecommons.org/licenses/by-nc-nd/4.0/

\section{LICENCE}

CC BY-NC-ND 4.0

\section{REPOSITORY RECORD}

Acar, Memis, and J.F. Harper. 2017. "Textile Composites from Hydro-entangled Non-woven Fabrics". figshare. https://hdl.handle.net/2134/25686. 


\title{
Textile composites from hydro-entangled nonwoven fabrics
}

\author{
Memis Acar \& J.F. Harper
}

\begin{abstract}
Production of nonwoven fabrics and composite technology are not new areas. However it seems very little has been done to look at the potential of hydroentangled nonwovens as reinforcements in structural composites. A preliminary investigation is reported of the suitability of hydro-entangled nonwoven fabrics as fibre reinforcements in producing structural composites. Work reported involved producing various composite materials by impregnating hydroentangled fibrous structure with a suitable polymer and evaluating the composite properties via a number of tests, such as tensile strength and impact resistance. Preliminary results show that there is good potential for producing composite structures from hydro-entangled nonwovens.
\end{abstract}

Keywords: Hydro-entanglement; Nonwovens; Composites

\section{Introduction}

Common applications of textiles in structural composites involve lamination. Normally several layers of conventionally produced fabrics of the same or different materials are laminated in a sandwich structure, possibly with corrugated webs to impart stiffness and rigidity. Bonding techniques used between layers include chemical, adhesive and stitch bonding. Such laminates do not have fibre interlocking between layers and consequently, their failure by delamination under impact, compression and shear stress is not uncommon. Furthermore, the shapes that can be produced with laminates are limited, costly, and with hand lay up it is often difficult to maintain consistency.

There has been considerable interest in the development of composites structures which offer an alternative to conventional lamination and filament winding technologies. The driving force of this interest was the need to produce preforms for advanced composites with enhanced inter-laminar strength properties, improved damage tolerance as well as reduced manufacturing costs.

Braiding and weaving technologies have attracted significant attention in recent years leading to the development of sophisticated techniques to produce three-dimensional complex net shaped structures for textile reinforced composite production; knitting technology showing serious limitations. Fibrous assemblies have also been used in certain non-structural composite applications e.g. in the automotive industry and more recently in structural applications, particularly using resin transfer technology.

One of the areas which have not been fully exploited for composite applications is the fibrous assemblies usually ineptly referred to as 'nonwovens'. Such structures can be formed by various 
methods of bonding fibres together. A nonwoven is generally defined as a sheet or web structure made by bonding and interlocking fibers by mechanical, thermal, chemical or solvent means. Hydro-entanglement is an alternative method of bonding fibres together by using very fine high- pressure water jets.

The European definition from EDANA (European Disposables and Nonwovens Association) is similar to that of ISO (International Organisation for Standardisation) which defines a nonwoven as a manufactured sheet, web or batt of directionally or randomly orientated fibres (not yarns or rovings) bonded by friction and/or cohesion and/or adhesion [1].

There are primarily two stages to nonwoven production: web formation and consolidation, which can be followed by finishing [2,3]. A web can be made of randomly or directionally orientated fibres and is produced by one of the following methods: dry-laying, wet-laying, spun-laying and meltblowing. Once a web is formed it can be consolidated using one or more of the following means: chemical, solvent, thermal and mechanical bonding.

The field of nonwovens is very broad and the wide range of manufacturing processes gives rise to a large variety of properties. This makes them suitable for a number of applications: floor coverings, geotextiles, furnishings, thermal insulation, wipes, protective clothing, medical applications and reinforcements in structural composites [2,3].

Composites are manufactured using nonwovens but not often as structural composites. Nonwoven technology has been applied to carbon fibres in making stiff mats by needle punching or stitching the web of fibres and possibly backing this with a woven scrim [4].

Of course, chopped glass fibres are used as non- woven mats for impregnation with plastic resin to pro- duce glass reinforced plastic, which is rigid and stiff for use in structural parts in the boat building industry

\section{Hydro-entanglement technique}

Hydro-entanglement (also referred to as spun-lacing or jet-lacing) is an alternative method of bonding together textile and high performance fibres and their blends by using very fine, high pressure water jets to produce nonwoven fabrics.

Such fabrics are normally produced by chemical or thermal bonding, and needle punching processes. Hydro-entanglement technology is now proving highly successful with increased production speeds at reduced costs yet still yielding a high strength fabric. It not only offers replacements for conventional nonwovens but also opens up new markets for innovative products [5]. Application areas of hydro-entangled nonwoven fabrics cover a wide range of fabric weights, from 20 to $500 \mathrm{~g} / \mathrm{m}^{2}$. A significant part of the hydro-entangled fabrics are used for disposable medical products (breathable, fluid and bacterial barrier fabrics - $60 \%$ of the market) due to the lint-free and clean nature of the fabric. Other applications include household pro- ducts and wipes (20\%), fusible textiles and textile inter- linings (15\%) and other applications (5\%) such as thermal apparel insulation, insulation (glass fibre webs), filtration, hydrophilic and hydrophobic laminates [6].

Hydro-entanglement, as an industrial process is a relatively new technique that began to appear in industry in the 1980s [7]. This unique process offers a great opportunity for expansion of the nonwovens market at a rate of $15-20 \%$ per annum [6]. During 1987-1995 the annual production rate of hydro-entangled nonwovens increased from 45 to 140 thousand tonnes [8]. 
Fine water jets used in the hydro-entanglement process offer an alternative to mechanical needle punching but without the disadvantages of the physical fibre damage and slow production rates associated with the latter. It also eliminates the need for chemical or thermal binding, reducing environmental pollution.

The principal components of a hydro-entanglement system, as shown in Fig. 1, include the following [2,9]:

- system of injectors with holes of 100-120 $\mu$ m in diameter arranged in rows with a 3-5 mm spacing and 30-80 holes per $25 \mathrm{~mm}$ with water pressures up to $250 \mathrm{bar}$;

- supporting fabric (conveyor belt) made of a fine woven metallic mesh;

- vacuum boxes under the supporting fabric to remove the water for filtration and re-cycling.

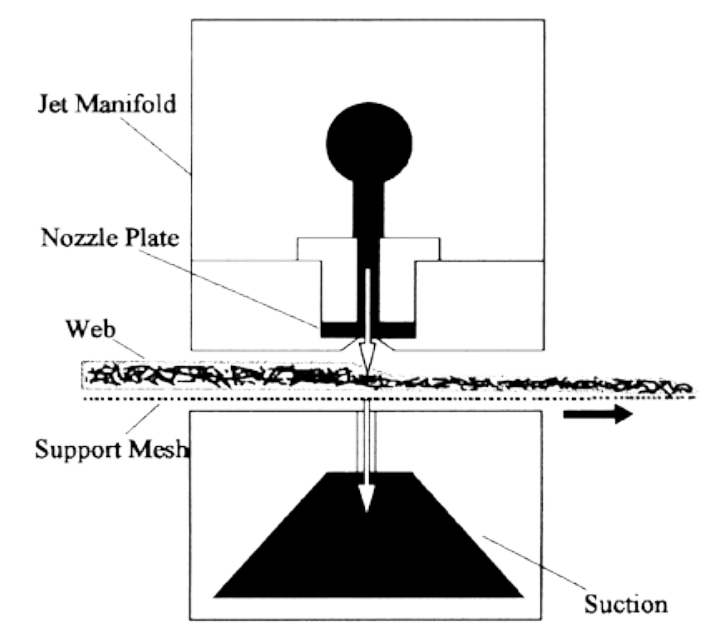

Fig. 1. Principal components of a hydro-entanglement system.

High-pressure water enters the jet manifold and exits through the nozzle plate that creates very fine water jets. As the emerging jets impinge upon the web they cause the fibres to entangle. The frictional forces resulting from the entanglement are the basis for mechanical bonding [10]. The compacted web travels on the support mesh, and takes up the pattern of the mesh. Excess water is removed by suction for filtering and recycling.

Hydro-entanglement seems a very suitable way of converting natural and synthetic textile fibres and their blends into nonwovens without damaging them and without the need for any additional binder. The hydro- entanglement process can be used to process not only all available textile fibres, but also new generation and high performance fibres, such as lyocel and aramid. The physical characteristics of the fabrics e.g. softness, hand, drape, are reminiscent of those conventional fabrics produced by weaving or knitting processes. The characteristics of fabrics can be engineered according to the end use requirement.

The advantage of hydro-entanglement over needle punching, the conventional form of mechanical bonding, is that with some fibres water acts as a plasticiser drastically reducing the bending stiffness, flexural rigidity and the torsional rigidity of the fibre. This allows the fibres to easily bend, twist, form loops, entangle, etc. under less force thereby bonding them together fairly easily. Besides, the use of water needles, instead of metal needles means less friction and 
hence less damage to the fibre. Both of these characteristics are important while processing specialty fibres used for composites. These high performance fibres, e.g. aramid, carbon, glass, etc. are not easily convertible using conventional nonwoven processes; they are prone to damage during processing and often need additional chemical binders to bond the fibres together.

Nowadays, high production speeds can be achieved as complete hydro-entanglement production lines come into use (capable of producing the fibres, then the web and finally a coherent fabric with a good surface finish) but obviously hydro-entanglement units can be added to existing web-forming machines [11].

\section{Hydro-entangled nonwovens for composites}

Hydro-entangled composites have the potential to be produced as one integrated structure of significant thickness as an alternative to laminates, consequently reducing de-lamination problems. Even when laminated it is expected that the hydro-entangled non- woven composites would offer much greater resistance to delamination due to the structure of the fabric, in that the fibres are intertwined and intermingled in all three directions improving cohesion between the laminae. A further advantage of the hydro-entangled nonwovens is that the flexibility and the compressibility of the nonwoven fabrics make them easier to mould into different shapes. Furthermore, hydro-entangled nonwovens absorb resin easily because of the high void volume of the fabric and this leads to composites with uniform distribution of fibres and resin throughout, resulting in excellent mechanical properties [12].

Hydro-entangled nonwovens can be produced in the form of apertured, crimped or corrugated forms. It is also possible to blend or multi-lay different fibres with different properties to impart desired strength, texture and surface qualities to the fibrous assembly. The production rate of the hydro-entanglement process is high, conversion cost is low, because it eliminates numerous textile processes between fibre web formation and fabric production.

Furthermore, the hydro-entanglement process has the potential to fuse or weld a multitude of pre-hydro- entangled fibrous assemblies together to produce three- dimensional profiles such as T-sections and I-sections. Such profiles are normally produced by three-dimensional weaving machines that incorporate an additional yarn filling perpendicular to the plane of warp and weft. Currently such machines that are in existence are very slow, cumbersome and costly. Furthermore, materials such as carbon fibres are not well suited for such three-dimensional textile processes.

\section{Composite sample preparation}

The aim of work reported here was to evaluate the suitability of hydro-entangled nonwoven fabrics and preforms for composites manufacture. As preliminary work flat hydro-entangled nonwoven fabrics were used to produce fibre reinforced composites. A general purpose polyester resin was used as the matrix for the composites since it is widely used today and has been used as the matrix for glass reinforced composites for over 40 years. Properties of the clear cast (i.e. pure) cured polyester resin were: density, $1.28 \mathrm{~g} / \mathrm{cm}^{3}$, modulus of elasticity, $2.5 \mathrm{GPa}$; tensile strength, $45 \mathrm{MPa}$; percentage elongation (strain at break), $2 \%$. Courtaulds Engineering Ltd supplied four samples of hydro-entangled nonwoven fabrics (Table 1). These were neither ideal nor purpose designed samples. Nevertheless they provided 
us with an opportunity to carry out some preliminary experiments. All four samples were airlaid to produce a multi-directional (i.e. randomly orientated) web of fibres, and then hydroentangled to consolidate the web into a fabric.

Flat panels were manufactured in order to carry out tests to enable assessment of basic properties of the basic composites. In this preliminary study of hydro-entangled nonwoven fabric composites a simple hand lay-up method of manufacture aided by hot pressing was used to produce 3-mm flat panels. The press was preheated to $60^{\circ} \mathrm{C}$ to reduce the cure time of the resin. After 20 min the mould was removed from the press. The panels were post- cured in an oven at $120^{\circ} \mathrm{C}$ for $30 \mathrm{~min}$, in order to complete the cure and enhance the mechanical properties of the resin.

Table 1. Properties of Initial composite samples

\begin{tabular}{llllll}
\hline Fabric sample & $\begin{array}{l}\text { Fiber density } \\
\left(\mathrm{g} / \mathrm{cm}^{3}\right)\end{array}$ & $\begin{array}{l}\text { Tensile strength } \\
(\mathrm{MPa})\end{array}$ & $\begin{array}{l}\text { Modulus of } \\
\text { elasticity }(\mathrm{GPa})\end{array}$ & $\begin{array}{l}\text { Fabric density } \\
\left(\mathrm{g} / \mathrm{m}^{2}\right)\end{array}$ & $\begin{array}{l}\text { Fabric thickness } \\
(\mathrm{mm})\end{array}$ \\
\hline $\begin{array}{l}\text { 100\% Polyester } \\
\text { 100 Viscose }\end{array}$ & 1.39 & 55 & 2.4 & 215 & 1.4 \\
$\begin{array}{l}\text { 33\% Viscose/33\% Polyester/ } 1.27 \\
\begin{array}{l}\text { 34\% Plyproplene } \\
\text { 100\% Polyester }\end{array}\end{array}$ & 1.52 & 18 & 2.9 & 100 & 0.8 \\
\end{tabular}

Initially four 3-mm thick samples were produced in an attempt to gain an insight into how the different fabrics and fibres affected the resulting composite. The number of layers in the composite samples was varied so that the volume fractions would stay consistent. This was because the fabrics varied in thickness (i.e. viscose being the thinnest). Two further 3-mm composite samples were made using the thicker polyester mat to look at the effect of varying the fibre volume fraction in the compo- site. Finally, one further composite was produced which was half as thick ('"1.5 mm) using one layer of the Viscose/Polyester/Polypropylene mat. (Table 2).

Table 2. Initial composite samples

\begin{tabular}{llll}
\hline $\begin{array}{l}\text { Composite } \\
\text { sample no. }\end{array}$ & Fabric type & Number of layers & $\begin{array}{l}\text { Resulting fibre volume } \\
\text { fraction (\%) }\end{array}$ \\
\hline 1 & $100 \%$ Polyester $\left(215 \mathrm{~g} / \mathrm{m}^{2}\right)$ & 2 & 11 \\
2 & 4 & 10 \\
3 & $100 \%$ Viscose & 2 & 13 \\
4 & Visc./Polyester $/ \mathrm{PP}$. & 1 & 11 \\
5 & $100 \%$ polyester $\left(450 \mathrm{~g} / \mathrm{m}^{2}\right)$ & 2 & 22 \\
6 & $100 \%$ polyester $\left(450 \mathrm{~g} / \mathrm{m}^{2}\right)$ & 3 & 33 \\
7 & $100 \%$ polyester $\left(450 \mathrm{~g} / \mathrm{m}^{2}\right)$ & 1 & 13 \\
\hline
\end{tabular}


Having completed the tests with these composites a single type of fibre was used to produce fabrics under varying hydro-entangling processing conditions to evaluate the effect of some process parameters on the composite properties; $100 \%$ polyester fibre was chosen as the material. Water jet pressure (from 100 to $160 \mathrm{bar}$ ) and production speed (from 5 to 20 $\mathrm{m} / \mathrm{min}$ ) were chosen as process parameters. Four layers of fabric were used in composite fabrication.

\section{Results and discussion}

\subsection{Tensile properties}

Tensile tests were performed using a J.J. Lloyd universal test machine at an extension rate of $10 \mathrm{~mm} / \mathrm{min}$ to produce failure within the standard specified time interval. The extension of the specimen was measured from the separation of the test machine jaws and the load directly from a $10 \mathrm{kN}$ in-line load cell. A PC interface and data logging was used to record the results which were presented in the form of load extension curves. The tensile modulus of the specimens was taken as the secant modulus, because of the non-linear elastic behaviour of the materials, calculated between 200 and $800 \mathrm{~N}$ where elastic deformation was occur- ring. The fracture surface morphology was studied using optical and scanning electron microscopy.

During tensile testing the samples made from low- density polyester fabric (1) initially deformed elastically before yielding and plastically extending with a linear increase in load to final failure at an average extension of $14.5 \%$, as depicted by a typical load-elongation curve (Fig. 2a). These samples exhibited the highest tensile strength per unit volume of fibres due to the high tensile strength of the fabric material. When incorporated at the same volume fraction in the resin the high-density polyester fabric (4) produced a similar general load deformation curve but with many peaks and troughs during plastic deformation which were ac- companied by cracking sounds from the specimen (Fig. 2b). These were believed to be due to local failure of the matrix and fibres in the more entangled structure.

Final failure of these specimens occurred at a lower average load (Fig. 3a) but slightly higher average extension of $17.5 \%$ (Fig. 3b) which would be indicative of the failure process. Their modulus was also slightly lower than for the low-density fabrics probably indicating that some disentanglement of fibres was already occurring during the elastic deformation stage.

A one and two fold increase in the volume fraction of fibres using the high density fabric in samples (5) and (6) produced a linear increase in tensile strength as would be expected from the rule of mixtures. The elastic modulus exhibited very little change as the modulus of the polyester fabric was very similar to the modulus of the polyester resin it replaced. However extension to failure increased from 17.5 to 35 and 42\%, with 11, 22 and 33\% volume fraction of fibres respectively. This was unexpected and can only be explained by the closer packing of the tangled fibres in the composites hindering disentanglement and fibre pull-out. This explanation is supported by the fact that the peaks and troughs in the plastic region of the load deformation curve became more numerous but, less severe, thus smoothing the curve. 

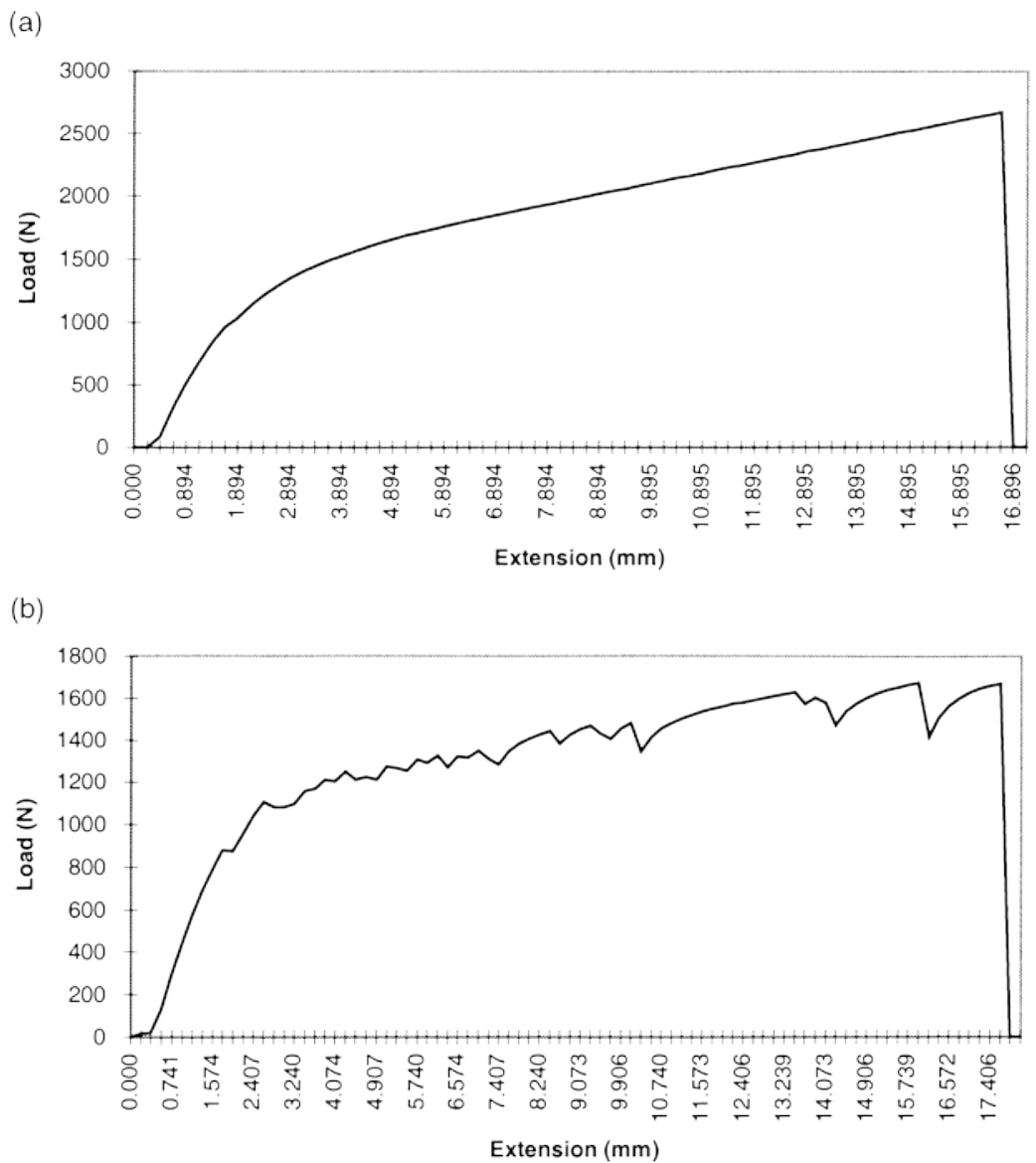

Fig. 2. (a) A typical load elongation curve for composite sample 1. (b) A typical load elongation curve for composite sample 4 .

The composite samples made from $100 \%$ viscose fabric (2) were not as strong in tension as the polyester (Fig. 3a) but their modulus was higher (Fig. 3c) due to the much lower tensile strength but higher modulus of the fabric. During testing they exhibited non-linear elastic behaviour up to a very distinctive yield point after which they continued to extend with only a small increase in load to failure at a relatively small average extension of $4 \%$. The mixed fibre fabric (3) could ultimately prove to be the most interesting material of the three. Its tensile strength was similar to that of the viscose material where a slightly higher value might have been expected, but its modulus was nearly $75 \%$ greater than either of the other two fabrics even though it contained 33\% polypropylene, which has a very low modulus. It exhibited no obvious yield behaviour with the tensile load steadily increasing to failure at an average extension of just over 2\%. An initial examination of the fracture did not aid in an understanding of these properties and further work is required, possibly with systematically varied percentages of each fibre. 
(a)

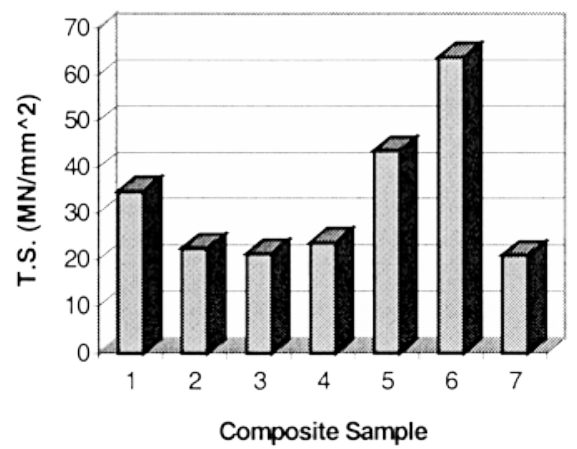

(b) Extensions at Failure

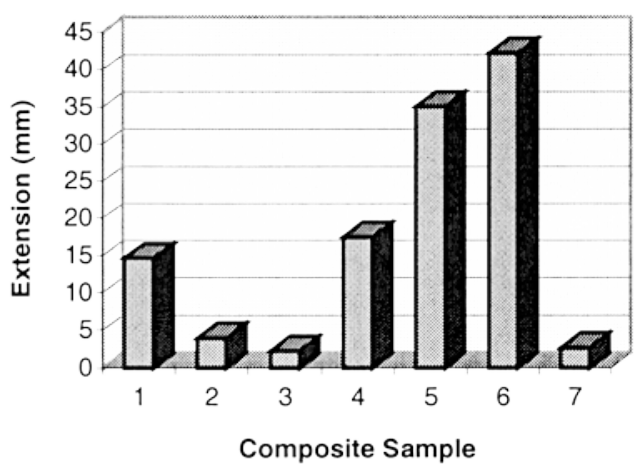

(c) Moduli of Elasticity

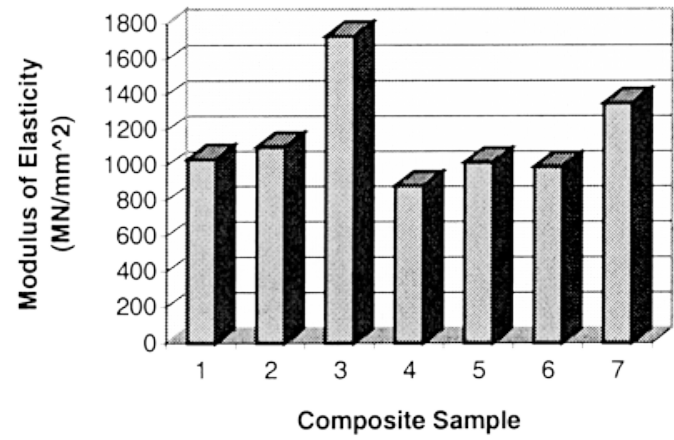

Fig. 3. (a) Tensile strength of the composite samples. (b) Extension at failure of the composite samples. (c) Tensile modulus of the composite samples.

\subsection{Impact properties}

The impact properties of the composites were assessed using an instrumented falling weight test that utilised a $10 \mathrm{~mm}$ hemispherical indenter at a velocity of $3 \mathrm{~m} / \mathrm{s}$. The specimen took the form of a single sample of the composite approximately $65 \mathrm{~mm}^{2}$, cut from the moulded laminate, and clamped between two steel support rings with inside diameters of $40 \mathrm{~mm}$. The central deformation and energy absorbed by the specimen were recorded at crack initiation and final failure. All of the results suffered from a high degree of scatter (Table 3).

With the exception of the sample containing viscose fabric, failure occurred by the indenter penetrating the composite and creating a truncated conical hole, with a diameter of 10-12 $\mathrm{mm}$ on the top surface and 14- $16 \mathrm{~mm}$ on the bottom, with fragments of the displaced material still attached. Similarities between the failures of the two polyester fabric containing composites were however, limited to their failure appearance. Crack initiation occurred at a much smaller force $(461 \mathrm{~N})$ and deflection $(1.9 \mathrm{~mm})$ in the high density fabric compo- site as compared with the lower density material (713 N and $2.95 \mathrm{~mm}$ respectively). Surprisingly therefore, this high density material ultimately absorbed a failure energy 60\% higher and final failure occurred at a de- formation of $13 \mathrm{~mm}$ compared with $6.9 \mathrm{~mm}$. Observation of the force/deflection trace for the test revealed an explanation. As with the tensile test the trace 
had many peaks and troughs, due to multiple crack initiation, propagation, and fibre pull out. All these failure processes are energy absorbing mechanisms and indeed are encouraged in composites where impact resistance is a priority. The corresponding trace for the low-density material was smooth and approximately sinusoidal in appearance.

The composite manufactured using the viscose fabric was much more brittle in nature with a disk of material, up to $30 \mathrm{~mm}$ in diameter; being completed 'smashed' from the test sample. Fibre ends only protruded a short distance from the fracture face. The hole left by this failure was surrounded by concentric cracks on the top surface and radial cracks on the underside. The total energy absorbed in fracture was the lowest recorded for all the samples even though the central deformation at final failure was higher than for the low-density polyester. Again the mixed fibre fabric produced an interesting result. Of all the samples it required the greatest force and deflection to initiate failure and the total energy absorbed in failure was better than for the low-density polyester and viscose fabric composites. At this stage in the investigation it can only be speculated that the combination of fibres had a synergistic toughening effect.

\subsection{Fractography}

A scanning electron microscope was used to study the fracture surfaces of the tensile specimens. All the samples appeared to be thoroughly wetted-out with micro-porosity only being evident in the mixed fibre composite and even then to a limited extent. The low volume fraction of fibres in all samples was apparent and hence resin rich areas were clearly visible but particularly between the layers of fabric.

Figs. 4 and 5 show the fracture surfaces of the low and high-density polyester samples respectively. The degree of entanglement of the fibres is visible in both samples as are the large number of pullout fibres and holes left by such fibres. Also apparent in both are the clean surfaces of the fibres indicating that no chemical bonding took place between the fibres and resin matrix. The major difference is the length of fibre pull- out, this being much greater for the high-density fibre sample (Fig. 5b). This difference accounts for the relative mechanical properties of the two samples. Fibre pullout occurs when the tensile strength of the fibre exceeds the maximum shear stress resulting from the adhesion of the fibre to its surrounding matrix. If the adhesion is low then the pullout length and number of fibres pulling out is high.

Table 3. Impact properties of hydro-entangled fabric composites

\begin{tabular}{|c|c|c|c|c|c|}
\hline Sample & $\begin{array}{l}\text { Peak force } \\
\text { (N) }\end{array}$ & $\begin{array}{l}\text { Peak energy } \\
(\mathrm{J})\end{array}$ & $\begin{array}{l}\text { Peak deflection } \\
(\mathrm{mm})\end{array}$ & $\begin{array}{l}\text { Failure energy } \\
\text { (J) }\end{array}$ & $\begin{array}{l}\text { Failure deflection } \\
(\mathrm{mm})\end{array}$ \\
\hline $\begin{array}{l}\text { Low-density } \\
\text { polyester }\end{array}$ & 713 & 1.3 & 2.95 & 3.4 & 6.9 \\
\hline $\begin{array}{l}\text { High-density } \\
\text { polyester }\end{array}$ & 461 & 0.44 & 1.9 & 5.4 & 13.0 \\
\hline Viscose & 418 & 0.42 & 1.9 & 2.4 & 9.8 \\
\hline \multicolumn{2}{|c|}{ Viscose/pe/pp mix754 } & 1.5 & 3.2 & 4.6 & 8.6 \\
\hline
\end{tabular}


(a)

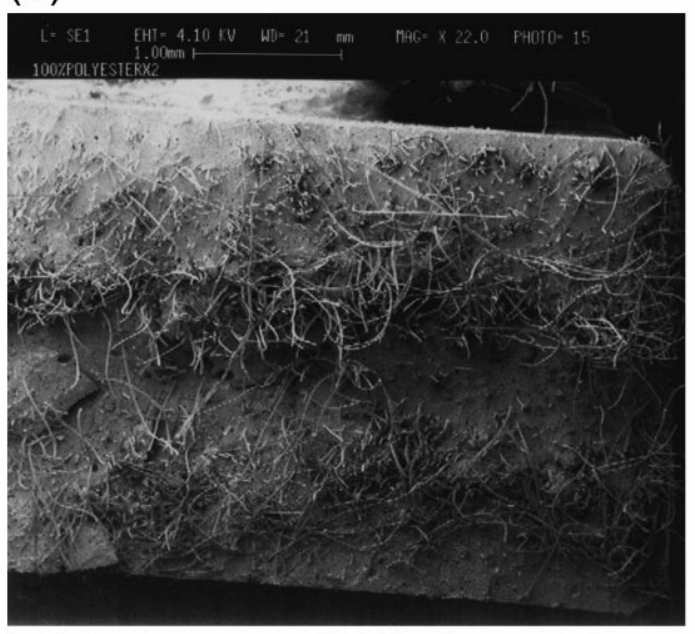

(b)

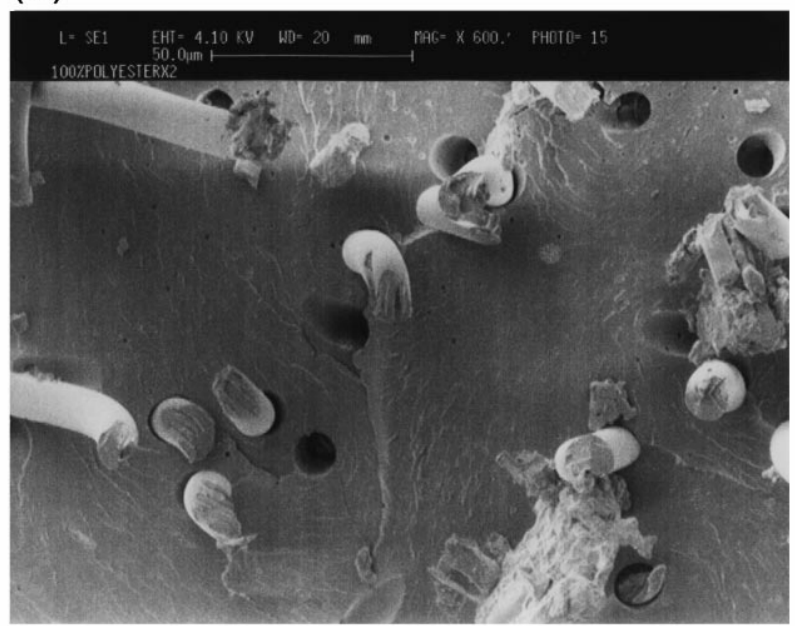

Fig. 4. (a) Composite sample 1. (b) Composite sample 1 close-up.

This is the situation for the high-density polyester fabric. It results in a low strength tough composite, because the strength of the fibres is not fully utilised but yet the process of pulling the fibres from the matrix requires large amounts of energy. In the low- density polyester fabric composite, (Fig. 4b), pullout lengths for similar strength fibres are shorter, which corresponds with a higher strength lower impact resist- ant composite as measured.

(a)

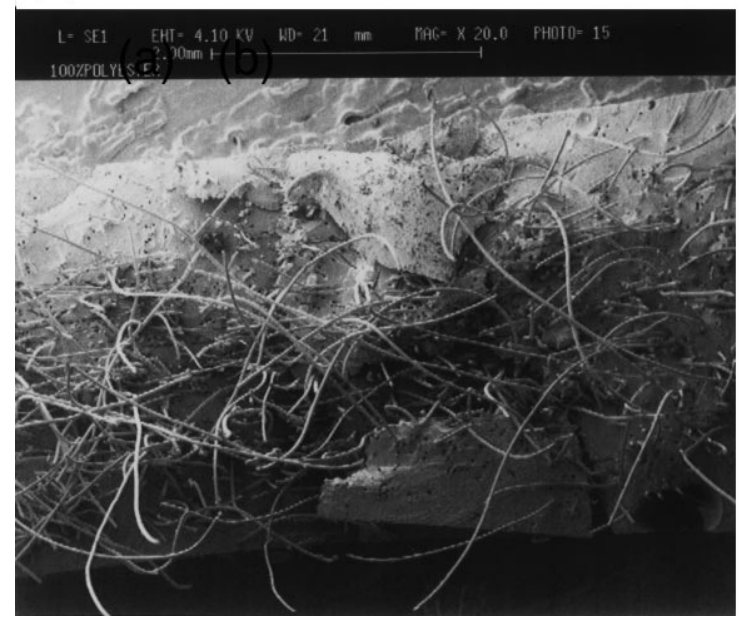

(b)

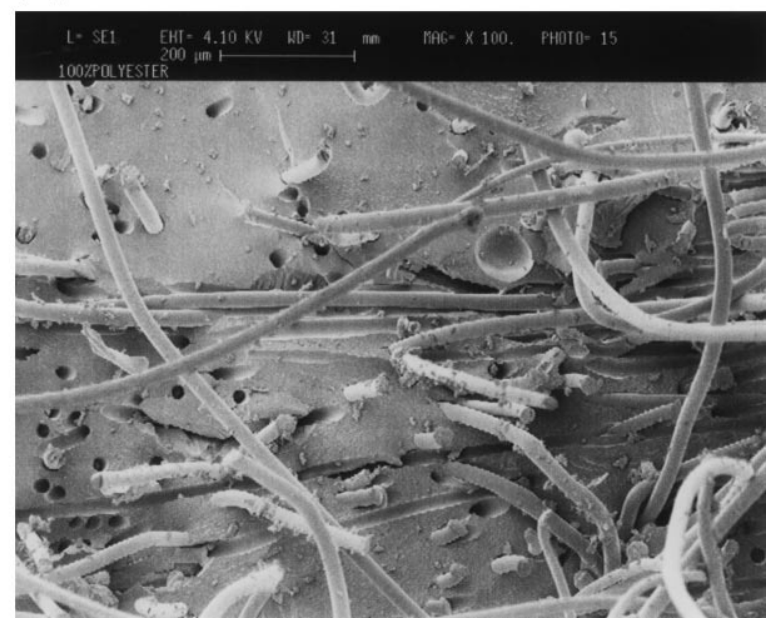

Fig. 5. (a) Composite sample 4. (b) Composite sample 4 close-up.

The fracture surface of the viscose fabric sample is shown in Fig. 6a. Immediately apparent are the resin rich areas between the layers of fabric. However, more significant are the very short lengths of fibre pullout and the longitudinal serrated surface texture of the fibres (Fig. $6 b)$. This surface texture would result in better adhesion between the fibre and matrix, due to mechanical bonding, and hence a greater interfacial shear strength and load transfer to the 
fibres. This coupled with the lower fibre strength, would result in fibre fracture rather than pull out, and hence explain the brittle failure observed. As was to be expected the fracture surface of the mixed fibre composite revealed a combination of the types of failure described above. Viscose fibres contributed to strength, with little pull- out, whereas the greatest contribution of the polyester fibres was to toughness.

(a)

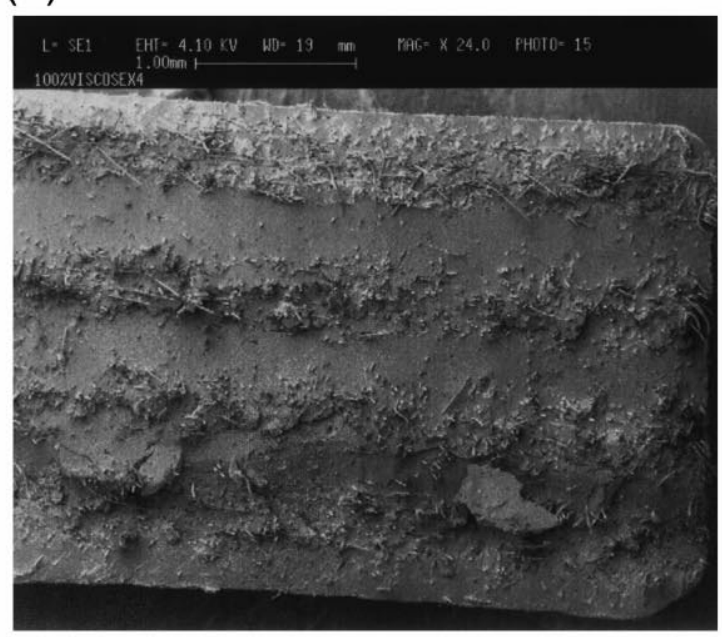

(b)

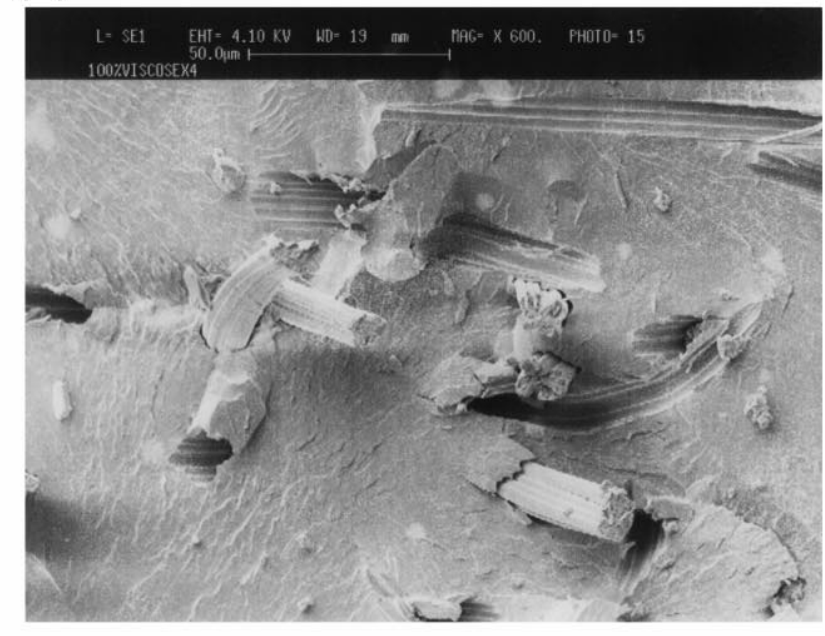

Fig. 6. (a) Composite sample 2. (b) Composite sample 2 close-up.

\subsection{Influence of hydro-entanglement variables}

SEM micrographs of the fabrics produced at 100 and 160 bar pressures showed significant differences in the entanglement level of the fibre. This is due to the hydro-entanglement, which results from higher pressures and consequently should result in a tougher fabric.

After the composite panels had been manufactured, tensile strength, open hole tensile strength and impact tests were conducted to determine mechanical proper- ties. Both the tensile and impact tests exhibited little difference between the samples tested, which indicates that the hydro-entanglement variables had little effect over the limited range used. This conclusion may be a little premature and more results are needed over a wider range of process speeds and water pressures.

Inspection of outer surface of samples showed that the interface cracking had occurred. This is believed to be due to a weak bond between the fibres and the resin, which in turn reduces the stiffness of the compo- site. Similar inspection of the fracture surface showed broken fibres and holes where fibres have pulled out. This is a further evidence of weak interface bonding where the tensile strength of the fibres exceeded the maximum shear stress of the fibre/resin interface. Such fibre pullout results in increased composite toughness.

\section{Conclusions}

Hydro-entanglement of nonwoven fibres offers an alternative method of producing preformed fabrics for reinforced plastics with high energy absorbing proper- ties. Hydro-entangled 
fabrics with short staple length fibres offer particular potential for improvements in impact resistance. The use of mixed fibre 'hybrid' fabrics demonstrated possible synergistic improvements in properties, which require further investigation. Future work will include this topic together with the use of engineering fibres and fibre blends such as aramid and glass at higher volume fractions.

\section{Acknowledgements}

The work reported in the current paper has been carried out by D Morris and O Tomlin, students in the Department of Mechanical Engineering, using the facilities of the Institute of Polymer Technology and Materials Engineering (IPTME) of Loughborough University of Technology, under the joint supervision of the authors. We also gratefully acknowledge the collaboration and assistance that we received from Courtaulds Engineering Ltd.

\section{References}

[1] Batra SK, Hersh SP, Baker RL, Buchanan DR, Gupta BS, George TW, Mohamed MH. Neither woven nor knitted. Textile Horizons, July 1986.

[2] Vaugn EA. Nonwovens as substrates for coated fabrics. Journal of Coated Fabrics 1992; 21.

[3] Brody H. Synthetic Fibre Materials. Polymer Science and Technology Series 1994.

[4] Boyer DC, Carlos DD, Kiser FH, Newman JW. Nonwoven carbon fiber composites. Tappi Journal, May 1990.

[5] Moore GK. Aspects of nonwoven bonding - the development and potential of hydroentanglement. In: TAPPI Proceedings, Nonwovens Conference, Nashville, TN, USA, 5-8 April, 1988.

[6] Rueher JA. Recent development in water-jet consolidation. In: Proceedings of Sixth Nonwovens Seminar, Hof, Germany, 14 November, 1991.

[7] Daily CM. Aspects of hydraulic entanglement technology. Tappi Journal 1988; 139(9), 152-4.

[8] Munstermann U,. Aquajet for lyocell fiber nonwovens. Chemical Fibers International 46(6); 457-458.

[9] White CF. Hydro-entanglement technology applied to wet-formed and other precursor webs. Tappi Journal June 1990.

[10] Bhat GS. Nonwovens as three-dimensional textiles for composites. Materials and Manufacturing Process 1995; 10(4), 667-8.

[11] Nitto Boseki Co. Ltd., Opening fabrics with hydrojets, High Performance Textiles, October 1990.

[12] Bhat GS. Nonwovens textiles for the manufacture of composites. In: Proceedings of the ASME Materials Davison, 1995; 69. 799-815. 